\title{
Treating Cancer with Snake Venom and Serum: Case Series
}

\section{Federica Facchin ${ }^{1,6}$, Margherita Ciano ${ }^{1,2}$, Silvia Canaider ${ }^{1,6}$, Fernando Ferretti ${ }^{3}$, Anna Ferretti ${ }^{3}$, Gianluigi Veronesi ${ }^{3}$, Stefano lotti ${ }^{4,6 *}$ and Pierluigi Lenzi ${ }^{3,5,6}$}

${ }^{1}$ Department of Experimental, Diagnostic and Specialty Medicine (DIMES), University of Bologna, Italy

${ }^{2}$ Section of Molecular Medicine, National Heart and Lung Institute, Imperial College London, UK

${ }^{3}$ Institute Of Human Physiology, University Of Bologna, Italy

${ }^{4}$ Professor of Biochemistry, Department of Pharmacy and Biotechnology, University of Bologna, Italy

${ }^{5}$ Former professor of Physiology, Faculty of Medicine, University of Bologna, Italy

${ }^{6}$ National Institute of Biostructures and Biosystems, Rome, Italy

\begin{abstract}
Introduction: A new anti-cancer immunological approach devised and experimented for years by Dr. Fernando Ferretti, is presented. Cobra Venom Factor is incubated with filtered Naja Naja Kaouthia serum and the mix obtained is injected subcutaneously. Due to the close functional similarity between Cobra Venom Factor and human Complement C3b, as well as the likely similarity between their inhibitors, the induced antibodies are hypothesized to cross react with Complement inhibitors and help restore the immune anti-cancer mechanisms.
\end{abstract}

Methods and results of mix component analysis: The electrophoretic analysis of Cobra Venom Factor, Naja serum and the therapeutic mix was performed and it showed that complex interactions occur between Cobra Venom Factor and serum, leading to the formation of new molecules in the mix.

Case report: We describe 8 cases of cancer treated with the present approach. Following immunogen injections, the patients generally experienced a transient increase in pain in the regions of primary and secondary cancer lesions, then the pain reduced and they felt better that before the injection. Overall, the effects observed ranged from complete healing to an increase of life duration beyond medical expectancy, together with a state of general wellbeing, decrease or disappearance of pain, new energy, a new positive sense of life.

Discussion: This therapy is aimed at balancing the various molecular components of the immune system, so as to restore its natural antitumor activity. A specific link is suggested between mix immunogens and the malignancy process.

Keywords: Cancer; Complement inhibitors; Immunological therapy; CVF; NNK; SDS-PAGE

\section{Introduction}

New anti-cancer strategies are worth considering as conventional therapies are not always successful and the cancer death toll is still awfully high. Besides surgery, chemotherapy and radiotherapy, new hopes are oriented to the immune system potentialities $[1,2]$. It is now recognized that the immune system has the ability to identify and eliminate nascent tumor cells with no toxicity to normal tissue, together with long-term memory that can prevent cancer recurrence [3]. If some tumor cells escape detection, cancer may develop and such tumor cells, by the effect of the selective pressure exerted by the immune system, become progressively less immunogenic, so that tumor tolerance grows up [4]. New immune-based therapies are directed to break tumor tolerance and reactivate anti-tumor immunity to induce effective anti-tumor responses [5]. In this paper we present a new anti-cancer immunological therapy, studied and applied for years by Dr. Fernando Ferretti, aimed at restoring the proper functioning of the natural anti-cancer immune mechanisms, in particular the activity of the Complement System, which are likely impaired in cancer patients. This therapy is protected by US patent [6]. The Complement System plays a key role against invading bacteria by the Membrane Attack Complex forming pores and lysing the bacteria. Moreover, as a mediator between the innate and adaptive immune response, the complement system can directly neutralize viruses and modulate pathogen elimination [7]. Complement components may however be pathogenic in chronic diseases as atherosclerosis. For what concerns cancer, the relationship between complement and tumor cells is complex. On the one hand, the activated complement proteins through different mechanisms may lead to complement-mediated destruction of tumor cells. However tumor cells have natural mechanisms of selfprotection against the complement system, as membrane and soluble complement inhibitors released by tumor cells interfere with the activation of the complement cascade. On the other hand, complement proteins may also favor tumor growth and immunosuppression [7] The C3 molecule is a key component of complement, as it is involved in classical, lectin and alternative pathways. The alternative pathway not only serves as an individual activation pathway, but also provides an amplification loop of the classical and lectin pathways. The alternative pathway is continuously low level activated by the hydrolysis of C3 to $\mathrm{C} 3\left(\mathrm{H}_{2} \mathrm{O}\right)$ ("tick-over") and an initial $\mathrm{C} 3$ convertase $\mathrm{C} 3\left(\mathrm{H}_{2} \mathrm{O}\right) \mathrm{Bb}$ is formed in the presence of Factor B and Factor D. The C3 convertases from all pathways cleave $\mathrm{C} 3$ in the anaphylatoxin $\mathrm{C} 3 \mathrm{a}$ and the opsonin $\mathrm{C} 3 \mathrm{~b}$ and a final $\mathrm{C} 3$ convertase $(\mathrm{C} 3 \mathrm{bBb})$, if not prevented by inhibitors, is formed and cleaves more C3 [8]. Years ago Dr. Fernando Ferretti hypothesized that transformed cells secrete a molecule closely related to complement $\mathrm{C} 3 \mathrm{~b}$, capable of reacting with Factor B and forming a C3/C5 convertase. This would activate the alternative pathway and

*Corresponding author: Stefano lotti, Department of Pharmacy and Biotechnology, University of Bologna, Italy, Tel +39 051209 5625; E-mail: stefano.iotti@unibo.it

Received June 02, 2014; Accepted July 18, 2014; Published July 20, 2014

Citation: Facchin F, Ciano M, Canaider S, Ferretti F, Ferretti A (2014) Treating Cancer with Snake Venom and Serum: Case Series. Altern Integ Med 3: 167. doi:10.4172/2327-5162.1000167

Copyright: $\odot 2014$ Facchin F, et al. This is an open-access article distributed under the terms of the Creative Commons Attribution License, which permits unrestricted use, distribution, and reproduction in any medium, provided the original author and source are credited. 
lead to the lysis of the transformed cells through the lytic cascade and/ or the cell mediated cytotoxicity. This hypothesized molecule, named by Dr. Ferretti as RUHC3bL from "Relatively un-modulated human C3b like" [6], is supposed not to be regulated by fluid-phase and membrane-bound complement regulatory proteins and then to have long lasting action. Once secreted, two possible outcomes could result: either adequate complement activation occurs and the transformed cells are eliminated, or too much inhibitor are present and inadequate complement activation gives rise to inflammation but not cell elimination, so that a tumor may develop. Interestingly, complement inhibitors have been found on nearly all developed tumors and cancer cell lines that have been examined, while some studies indicate that complement-inhibitory proteins are up-regulated on tumor cells [9]. In most patients, chronic inflammation and immune suppression are the dominant effects in the tumor microenvironment [10]. The basic idea of Dr. Ferretti was to stimulate the production of antibodies against the inhibitors hindering complement activation. He exploited the close functional similarity between Cobra Venom Factor (CVF) and human C3b. In fact, CVF reacts with human Factor B and forms a $\mathrm{C} 3 / \mathrm{C} 5$ convertase, $(\mathrm{CVF}) \mathrm{Bb}$, which is not regulated by complement regulatory proteins and has long lasting action [11], as it is supposed to be for the hypothesized RUHC3bL molecule. Basing on the well-known resistance of snakes to their own venom, due among others to venom inhibitors present in their serum [12], Dr. Ferretti hypothesized that by incubating CVF with Naja serum, a mix would be obtained containing complexes of CVF or CVF fragments with inhibitors. These inhibitors are likely related to human $\mathrm{C} 3 \mathrm{~b}$ or RUHC3bL inhibitors, but are definitely non-self. Injecting this mix in cancer patients, the non-selfepitopes would stimulate the formation of antibodies hypothetically cross-reacting with human $\mathrm{C} 3 \mathrm{~b}$ and RUHC3bL inhibitors, thus enhancing complement activation and complement mediated attack against transformed cells. In this paper a sample of the clinical results obtained over the years by Dr. Ferretti's therapy, together with a preliminary analysis of the therapeutic mix and its components are presented. We underline that the present study is aimed at evaluating whether the serum-CVF interaction produce adducts that could be compatible with Dr. Ferretti hypothesis. Of course, to obtain a conclusive confirm to this hypothesis further and more detailed studies are needed.

\section{Case History}

\section{Patient characteristics and diagnosis}

Patients having received cancer diagnosis were considered. Two of the oldest cases, relative to the years 1965-1970, together with two more recent cases, are presented below. The oldest cases concern skin cancers, documented by their images. For the more recent cases, clinical information is available, documented by clinical reports. Four more cases are presented in supplementary information. The cases here reported are just a sample of the many cases treated over the years by Dr. Ferretti. Many of the patients treated by Dr. Ferretti had been abandoned by the medical establishment as the conventional therapy was no more effective. In other cases, the therapy was applied in parallel with standard treatments, outside the control of the official medical team. For patients abandoned by the medical establishment, only the direct observation by Dr. Ferretti, the patients themselves and their relative could account for the effects of the immunological therapy. For patients in follow-up, the effects of the immunological therapy could be inferred from the clinical information provided by the official medical team. In all cases the immunological therapy was applied on request and informed consent of the patient.

\section{Methods and Intervention}

\section{Immunological therapy}

Dr. Ferretti's immunological therapy is based on injecting in cancer patients a mix obtained by incubating CVF with Naja Naja Kaouthia (NNK) serum. The mix is prepared according to the procedure presented below. Doses and incubation times, as well as serum filter cut-off, were slightly modified over the years, aiming at optimizing the outcome. Pre-clinical toxicity of a mixture of whole NNK serum and its crude venom was evaluated in 1973 at the Institute of Pharmacology of the Bologna University. Acute and chronic toxicity in rats, embryotoxicity in rabbits and direct active anaphylaxis in the guinea pig were tested. At doses comparable with the therapeutic ones, no toxicity, either acute or chronic, was found in the mix analyzed. Dr. Ferretti started experimenting his immunological therapy on mice in the ' $60^{\text {th }}$ and the results obtained encouraged him to treat cancer patients. The cases here reported represent only a small sample of the many cases treated by Dr. Ferretti, who worked in the silence for more than 30 years to develop his therapeutic mix, engaging all his intellectual and economical resources, as he always applied his therapy for free in all the patients treated. Dr. Ferretti's therapy and mix are protected by US patent [6].

\section{Treatment}

Typically, a $500 \mu \mathrm{L}$ dose of the mix was injected subcutaneously at intervals ranging from 5 to 30 days, depending on patient reactions. The duration of treatment ranged from many months to years, as during the treatment the patients enjoyed a better quality of life. Some patients wanted to continue the therapy even if they felt healed.

\section{Composition of the therapeutic mix}

Two different mixes utilized over the years were considered, with serum $10 \mathrm{kDa}$ and $50 \mathrm{kDa}$ filter cut off (here named S10 and S50, respectively). The mixes were obtained according to the following procedure:

NNK serum and CVF were obtained from ACZON (BOLOGNA, ITALY). $2 \mathrm{ml}$ of NNK serum were diluted with $38 \mathrm{ml}$ of sterile distilled water and kept shaking for 20 minutes. The serum was filtered by centrifugal filter devices, with 10 or $50 \mathrm{kDa}$ cut off (AMICOM ULTRA-15 $10 \mathrm{~K}$ and 50K, MILLIPORE, IRELAND). The diluted serum was placed at the top of the filter and centrifuged $(5800 \mathrm{rpm} \times 60$ minutes $\times 4^{\circ} \mathrm{C}$ ). Filtrates were separately collected for $10 \mathrm{kDa}$ and 50 $\mathrm{kDa}$ filter cut-off. $200 \mu \mathrm{g}$ of CVF were mixed with filtrates, oscillated for 2 hours at $26^{\circ} \mathrm{C}$ and aliquoted.

The mix was concentrated to $7 \mathrm{ml}$ (SAVANT concentrator)The mix was filtrated through MILLEX Syringe Filter Unit $0.45 \mu \mathrm{m}$ (MILLIPORE, IRELAND) this mix yielded an overall volume of 7200 $\mu \mathrm{l}$. This mix was added with the following:- $3000 \mu \mathrm{L}$ of Aluminum Hydroxide 3\%, colloidal aluminum for subcutaneous vaccines approved by the Italian health authorities)

$110 \mu \mathrm{L}$ of Tyrosine $400 \mu \mathrm{M}$ solution. It is an adjuvant normally used in vaccines [13] (SIGMA, ST. LOUIS, MO)-110 $\mu \mathrm{L}$ of THIMEROSAL $(10 \mu \mathrm{g} / \mu \mathrm{l})$ (SIGMA, ST. LOUIS, MO).This amount lead to a final THIMEROSAL concentration of 1:10000. It is germicide, utilized for subcutaneous vaccines and once allowed by the Italian health authorities. The final volume of the above components was $10420 \mu \mathrm{l}$. The unit dosage is $500 \mu \mathrm{l}$. The mix obtained is thus equivalent to about 20 doses, every single dose containing $10 \mu \mathrm{g} C V F+10 \mu \mathrm{L}$ of $10 \mathrm{kDa}$ or 
Citation: Facchin F, Ciano M, Canaider S, Ferretti F, Ferretti A (2014) Treating Cancer with Snake Venom and Serum: Case Series. Altern Integ Med 3: 167. doi:10.4172/2327-5162.1000167

$50 \mathrm{kDa}$ cut-off filtered serum+other accessory adjuvants added (here named S10V and S50V, respectively).

\section{Native PAGE, SDS-PAGE and 2D-PAGE: CVF, serum and therapeutic mix protein analysis}

Protein content of each sample was determined with a BCA protein assay kit (PIERCE, PIERCE BIOTECHNOLOGY, and ROCKFORD, IL, USA) and NANODROP technologies (NANODROP ND 1000 v.3.8.1, WILMINGTON, DELAWARE, USA) were used for the quantification. The protein content of each sample was analyzed in both native and denaturing conditions. Preliminary tests were performed to find the correct protein balance to get a good visualization. For the NativePAGE, samples were diluted 1:4 with Native loading buffer $(62.5 \mathrm{mM}$ Tris- $\mathrm{HCl} \mathrm{pH} 6.8,40 \%$ Glycerol w/v, 0.01\% BPB) then shaken for 10 minutes. The electrophoresis was performed using gradient gels (4$20 \%$ precast polyacrylamide gel, BIO-RAD, MILANO, ITALY) with native buffer $(25 \mathrm{mM}$ Tris, $192 \mathrm{mM}$ Glycine $\mathrm{pH} 8.3)$ at $4^{\circ} \mathrm{C}$ to avoid denaturation due to high temperature.For the SDS-PAGE, samples were diluted 1:4 with denaturing loading buffer (1 M Tris base, $\mathrm{pH}$ 6.8, 8\% SDS, $20 \%$ Glycerol, $0.24 \%$ BPB, $4 \%$ beta-mercaptoethanol) and boiled for 10 minutes. SDS-PAGE was performed using a standard method on a vertical slab gel. Proteins were analyzed on $4-20 \%$ precast gel or $6 \%$ or $12 \%$ or $15 \%$ homemade polyacrylamide gels and the electrophoresis was performed with Glycine buffer (25 mM Tris, 192 $\mathrm{mM}$ glycine, $0.1 \% \mathrm{SDS}, \mathrm{pH} 8.3$ ) at room temperature.

To investigate the potential interaction between CVF and S10 proteins a two-dimensional polyacrylamide gel electrophoresis (2D-PAGE) was performed. Native PAGE as above was used for onestep isolation of protein complexes. The whole lane or the bands of interest were cut out, treated with $10 \%$ SDS for 15 minutes and placed on top of a $10 \%$ or $12 \%$ or $15 \%$ polyacrylamide gel and subjected to Glycine/SDS-PAGE [14].

After all the electrophoresis, the protein bands were visualized by staining with bio-safe COOMASSIE (BIO-RAD) or with silver stain using a mass spectrometry compatible protocol (161-0449 SILVER STAIN PLUS, BIO-RAD). PRECISION PLUS PROTEIN DUAL XTRA standards (BIO-RAD) were used as a molecular weight marker. The bands produced in the electropherogram were scored, and their molecular weights were compared with the standard protein marker.

\section{Results of Mix Component Analysis}

Native-PAGE (Native Polyacrylamide Gel Electrophoresis) of CVF showed three bands. Besides the expected $150 \mathrm{kDa}$ band [11], two more bands of about 70 and $75 \mathrm{kDa}$ appeared (Figure 1A). When CVF was analyzed with two-dimensional electrophoresis system (2D-PAGE), the three bands were confirmed in denaturing condition, indicating that no interactions were present in native CVF (Figure 1B). The SDS (Sodium Dodecyl Sulfate) - PAGE of CVF showed many bands (Figure 1C), including the three expected products $(69,45$ and $29 \mathrm{kDa},[11])$.

In both native-PAGE S10 and S50, a $70 \mathrm{kDa}$ band appeared (Figure 2A). To better visualize protein bands in SDS-PAGE of S10 and S50, several experiments were performed with different polyacrylamide gel concentrations $(4-20 \%, 6 \%, 12 \%, 15 \%)$. In all experiments, a $70 \mathrm{kDa}$ band was visualized (Figure $2 \mathrm{~B}$ ), while in some experiments up to three bands were present (approximately 70, 65 and $50 \mathrm{kDa}$, Figure 2C).

Two therapeutic mixes (CVF added to S10 or S50, here named S10V and S50V, respectively) were analyzed. Native-PAGE of S10V showed at least three bands corresponding to those of native CVF (150,

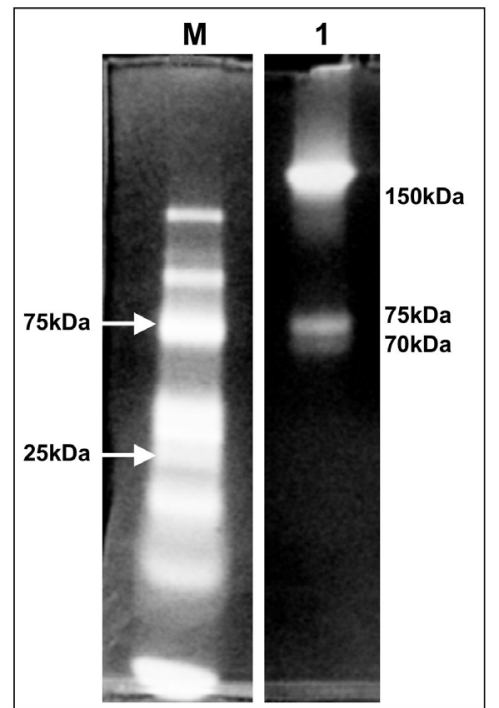

Figure 1a: CVF protein analysis. (A), Representative gel of $4-20 \%$ Native PAGE of CVF. Lane M, $5 \mu$ I Precision Plus Protein Dual Xtra standards marker. Lane 1, $15 \mu \mathrm{g}$ CVF sample.

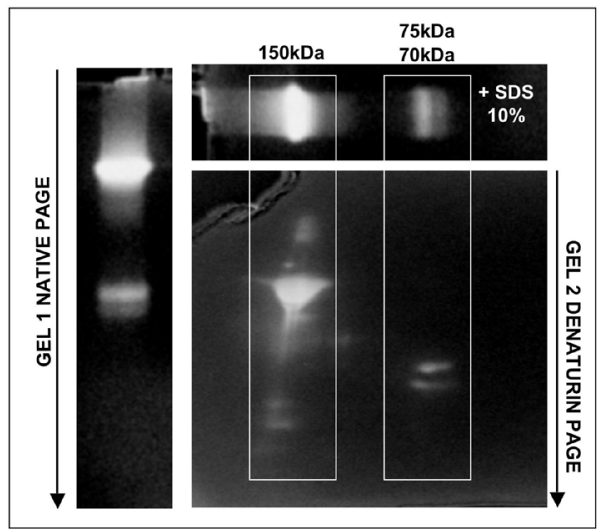

Figure 1b: 2D-PAGE of CVF. Gel 1 (left), CVF 4-20\% Native PAGE. Gel 2 (right), CVF $12 \%$ denaturing PAGE.

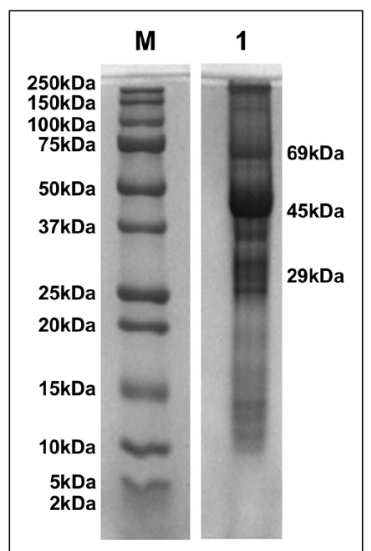

Figure 1c: Representative gel of $12 \%$ SDS-PAGE of CVF. Lane M, $5 \mu \mathrm{l}$ Precision Plus Protein Dual Xtra standards marker. Lane 1,15 ug CVF sample (arrows indicate expected size bands: 69, 45 and $29 \mathrm{kDa}$ ). The gels in Figure 1 resulted from three independent experiments. Gel staining was made with bio-safe comassie. 


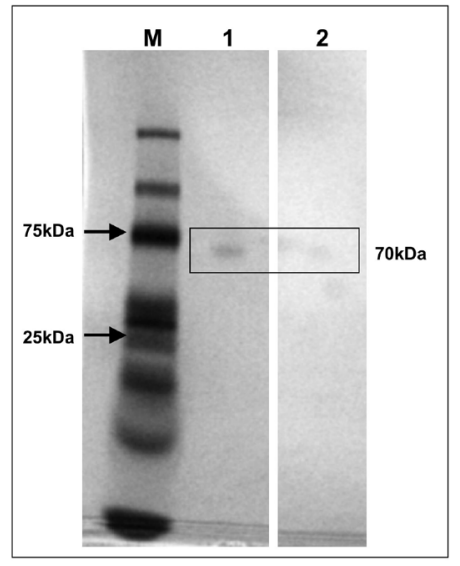

Figure 2a: S10 and S50 protein analysis. (A) Representative gel of $4-20 \%$ Native PAGE of S10 and S50. Lane M, $5 \mu \mathrm{l}$ Precision Plus Protein Dual Xtra standards marker. Lane 1, $60 \mu \mathrm{g}$ S10 sample. Lane 2, $95 \mu \mathrm{g}$ S50 sample. Gel staining by bio-safe comassie

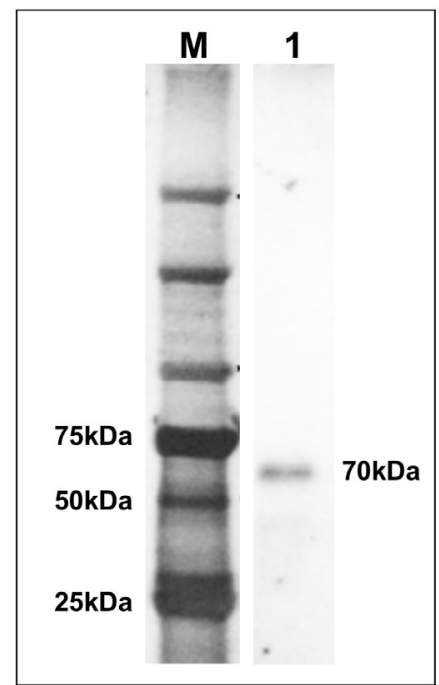

Figure 2b: Representative gel of S10 6\% SDS-PAGE of S10. Lane M, $5 \mu \mathrm{l}$ Precision Plus Protein Dual Xtra standards marker. Lane 1, $36 \mu \mathrm{g}$ S10 sample. Gel staining by bio-safe comassie.

75 and $70 \mathrm{kDa}$ approximately) or native $\mathrm{S} 10(70 \mathrm{kDa})$. Native-PAGE of S50V showed at least two bands (approximately 70 and $75 \mathrm{kDa}$ ) corresponding to those of native CVF and/or of native S50, together with another band (higher than $150 \mathrm{kDa}$ ), possibly representing the product of protein interaction (Figure $3 \mathrm{~A}$ ). All the bands obtained from $\mathrm{S} 10 \mathrm{~V}$ in native conditions (some of which detected also in S50V), were analyzed with 2D-PAGE (data not shown). The bands suspected to be the product of protein interaction $(>150 \mathrm{kDa})$ were analyzed at least three times in denaturing-condition electrophoresis and they revealed a single spot. After denaturation, the bands corresponding to native CVF revealed only one spot on the gel, in accordance with the previous CVF behavior (Figure 1B). SDS-PAGE of S10V showed many bands with molecular weight in the range 200 to $4 \mathrm{kDa}$ approximately (Figure 3B), while SDS-PAGE of S50V showed at least three bands (Figure 3C).

Both in S10V and S50V (Figure 3B and 3C) two bands (70 and 45/50 $\mathrm{kDa}$ approximately) could be assigned to $\mathrm{S} 10$ or $\mathrm{S} 50$ respectively and the $69 \mathrm{kDa}$ band to CVF, while in S10V bands with molecular weight lower than about $50 \mathrm{kDa}$ could be assigned to CVF (in particular 29 $\mathrm{kDa}$ band).

On the contrary, some SDS-PAGE CVF bands were not present in S10V or S50V and in the SDS-PAGE of S10V some bands were not easily assigned to CVF or S10, thus showing that molecular changes occurred in the therapeutic mix. Moreover, the CVF fragments appreciable in S10Vwere no more visible in S50V, demonstrating that proteolytic enzymes with molecular weight $>10 \mathrm{KDa}$ are present in serum,

The analysis of $\mathrm{S} 10 \mathrm{~V}$ showed the same band pattern before and after freezing $\left(-20^{\circ} \mathrm{C}\right)$. This has been verified with both native (Figure $4 \mathrm{~A}$ ) and SDS-PAGE (Figure 4B). The same evidence appeared for S50V (data not shown).

\section{Treatment Outcome}

\section{Case AB}

The first case treated by Dr. Ferretti was the patient $A B$, affected

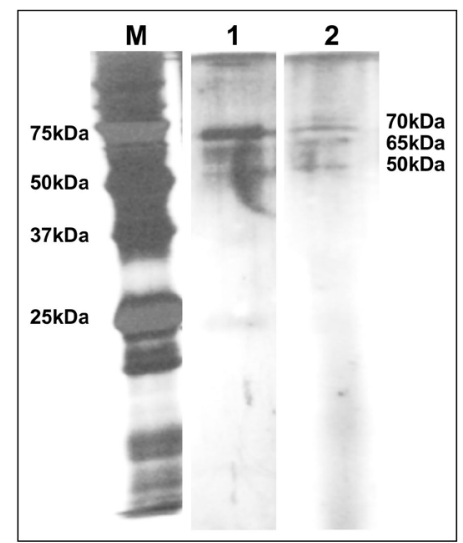

Figure 2c: Representative gel of $12 \%$ SDS-PAGE of S10 and S50. Lane M, $5 \mu \mathrm{l}$ Precision Plus Protein Dual Xtra standards marker. Lane 1, $36 \mu \mathrm{g} \mathrm{S10} \mathrm{sample.}$ Lane 2, $57 \mu \mathrm{g}$ S50 sample. Gel staining by silver. The gels in Figure 2 resulted from three independent experiments.

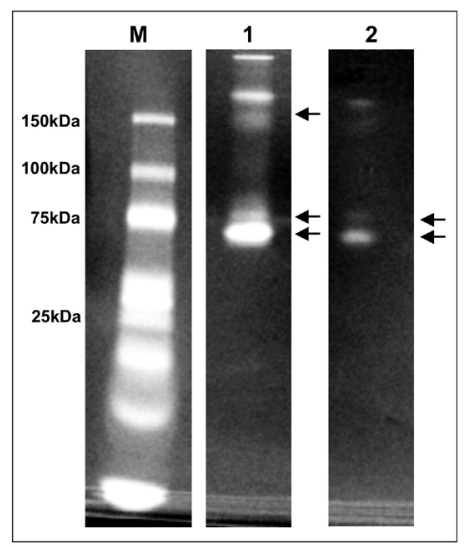

Figure 3a: S10V and S50V protein analysis. (A), Representative gel of 4-20\% Native PAGE of S10V and S50V. Lane M, $5 \mu$ Precision Plus Protein Dual Xtra standards marker. Lane 1, $100 \mu \mathrm{g} \mathrm{S10V} \mathrm{sample.} \mathrm{Lane} \mathrm{2,} 100 \mu \mathrm{g}$ S50V sample. The arrows indicate the bands assigned to CVF and/or S10 and S50 (see text). 


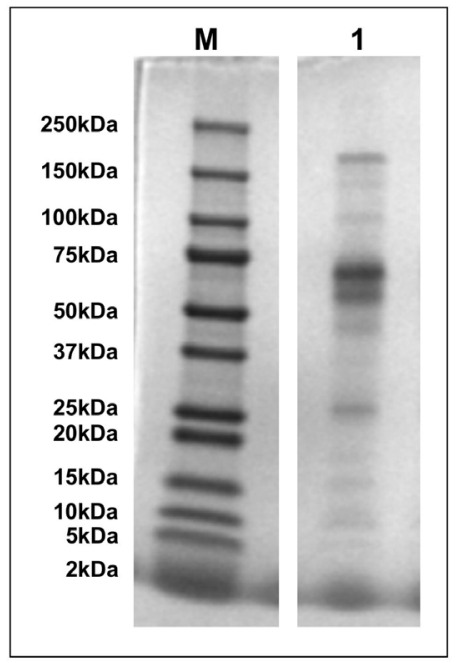

Figure 3b: Representative gel of $4-20 \%$ SDS-PAGE of S10V. Lane M, $5 \mu \mathrm{l}$ Precision Plus Protein Dual Xtra standards marker. Lane 1, $56 \mu \mathrm{g}$ S10V sample.

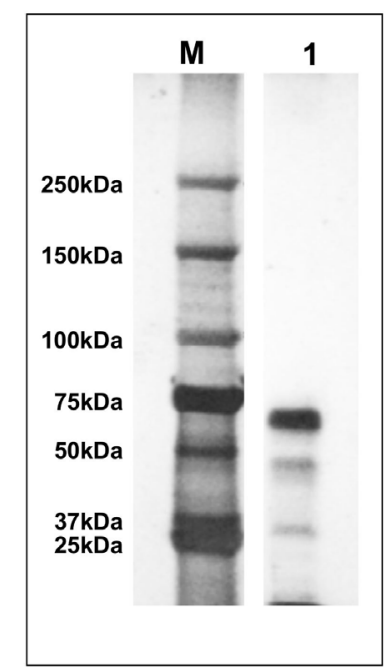

Figure 3c: Representative gel of $6 \%$ SDS-PAGE of S50V. Lane M, $5 \mu \mathrm{l}$ Precision Plus Protein Dual Xtra standards marker. Lane 1, $56 \mu \mathrm{g}$ S50V sample. All gels were stained with bio-safe comassie.

by a devastating squamous-cell carcinoma, with poor prognosis in the short term (Figure 5A), in 1965. The neoplastic lesion was characterized by irregular edges and colors and these traits recalled chronic inflammation and pathologic wound healing. This suggested to Dr. Ferretti that in neoplasms a C3-like protein was present, characterized by poor regulation and long lasting activity. A lesser duration would occur in chronic inflammation and pathologic wound healing. In Figure 5B the neoplastic lesion is displayed 60 days after the beginning of therapy. It appears that fibrinolysis was highly reduced, coagulation was getting normal and wound edges were drying up. The situation 90 days after the beginning of therapy is displayed in Figure 5C. It appears that fibrinolysis was further reduced, coagulation was effective, wound edges were dried and more regular. Eventually, cancer regressed, the edges healed and became dry and new epithelium developed. Pain ceased completely (painkillers passed from 8 to 1 per day at bedtime), as well as paresthesias, local circulatory alterations and hyperthermia.
The elderly patient resumed feeding and led a worth living life for 6 years, until he fell and fractured his femur. He died a few months later due to complications from pneumonia caused by immobilization.

\section{Case PB}

The patient $\mathrm{PB}$ had a hyper-fibrinolytic basal cell carcinoma in the back in 1969. In Figure 6A the neoplastic lesion before the beginning of the therapy is shown. In Figures 6B-6D the same neoplastic lesion is displayed 60, 90 and 120 days after the beginning of therapy, respectively. Eventually, the basal cell carcinoma regressed with dry scarring and re-epithelialization of the edges. Pain completely stopped, as well as regional parenthesis and alterations in macro- and microcirculation. Local hyperthermia ceased as well. The patient was still alive and in good health in 2005.

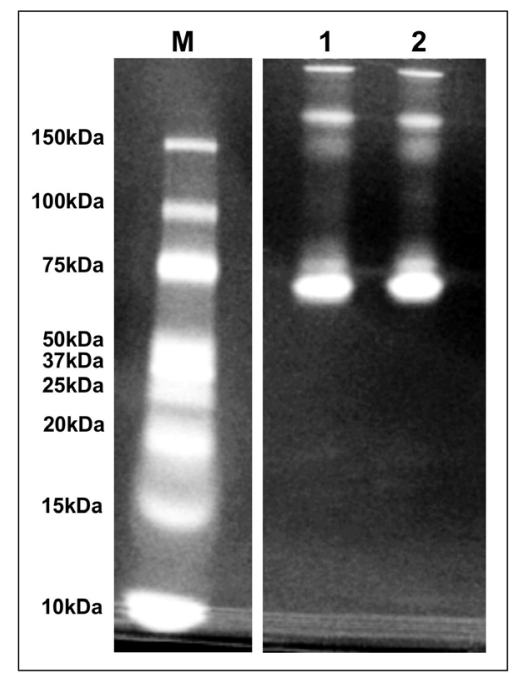

Figure 4a: Analysis of S10V before and after freezing. (A) Representative gel of 4-20\% Native PAGE. Lane M, 5 ul Precision Plus Protein Dual Xtra standards marker. Lane 1, $100 \mu \mathrm{g}$ S10V. Lane 2, $100 \mu \mathrm{g} \mathrm{S10V}$ (three times frozen and defrozen sample).

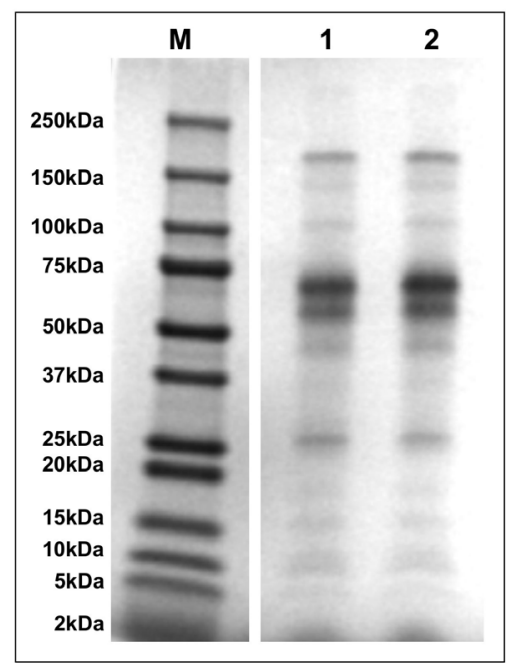

Figure 4b: Representative gel of $4-20 \%$ SDS-PAGE of S10V. Lane M, $5 \mu l$ Precision Plus Protein Dual Xtra standards marker. Lane 1, $56 \mu \mathrm{g}$ S10V. Lane $2,56 \mu \mathrm{g}$. S10V (after three times freezing and defreezing processes). Gels were stained by bio-safe comassie. 


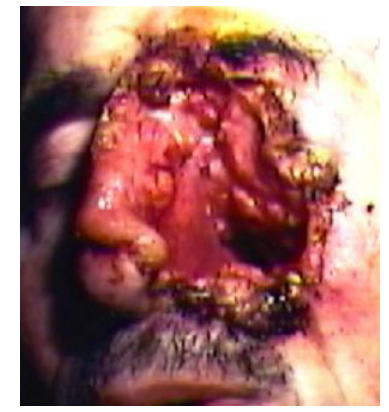

Figure 5a: Squamous-cell carcinoma in the left side of the face. (A) Before the beginning of the immunological therapy. An overall irregularity is apparent in edges and colors, with traits recalling chronic inflammation and pathological wound healing.

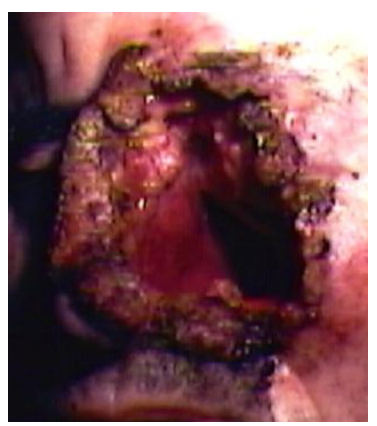

Figure 5b: 60 days after the beginning of therapy. Fibrinolysis was markedly reduced, clotting was getting normal and the edges of the neoplastic lesion were drying up.

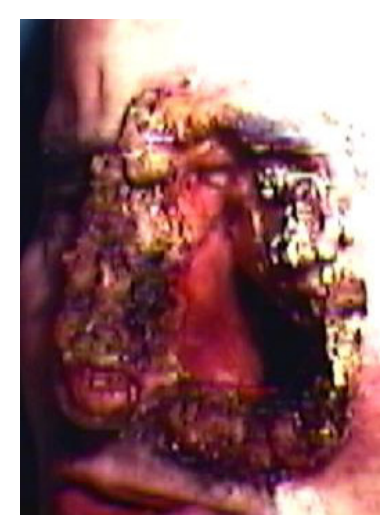

Figure 5c: 90 days after the beginning of therapy. Fibrinolysis was further decreased, clotting was effective, the edges of the neoplastic lesion were dry, less indented and more regular.

\section{Case GG}

GG was born in 1947. At the beginning of 1998, a swelling appeared in the medial part of the left thigh, near the groin, without pain or obstacles to walking. On June 26, the MRI performed on his left thigh led to the diagnosis of "solid neoplasm of about $9 \mathrm{~cm}$, suggestive of mixoid liposarcoma". On June 30, the CT scan of lower limbs, abdomen and chest, confirmed the previous data and, though not showing clear signs of secondary lesions, showed the presence of simildense tissue between pericardium and the aortic arch, as well as the enlargement of the left seminal vesicle. On July 7, on the basis of a biopsy specimen, the first histopathological diagnosis of "undifferentiated neoplasm, characterized by round cells with vacuoles and morphological features consistent with a round cell liposarcoma" was issued. From July 22 to late August 1998, antero-posterior tele-cobalt radiotherapy was applied in the left thigh, but on August 25 the CT scan showed that the known lesion was still present. On September 2, surgery was performed at Rizzoli hospital in Bologna and the histological examination of the surgical specimens supported the diagnosis of infiltrating pleomorphic liposarcoma, with large necrotic regions and reactive lymph adenitis. On September 16 the patient was discharged from the hospital with a drainage that leaked about $400 \mathrm{~mL} /$ day. Chemotherapy was prescribed (Zimat 500, Cytotec, Calciparin, Contramal, Ferrograd). On October 2, an opening $4 \mathrm{~cm}$ long formed at the surgical edge, with a marked loss

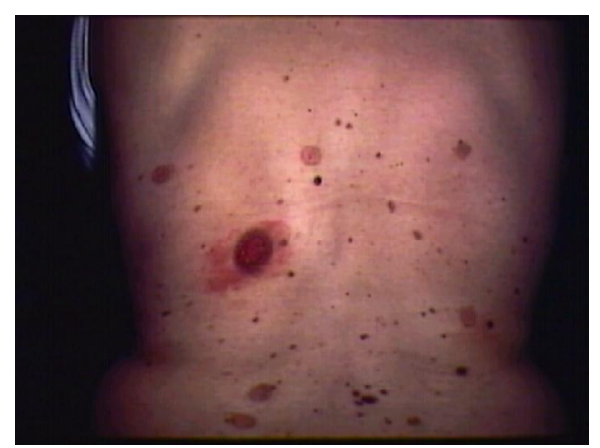

Figure 6a: Basal cell carcinoma. (A) before the beginning of the immunological therapy.

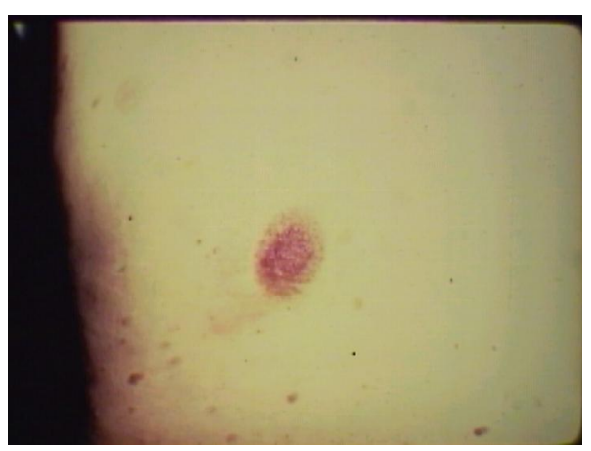

Figure 6b: The neoplastic lesion 60, 90 and 120 days after the beginning of therapy, respectively. The basal cell carcinoma regressed with dry scarring and re-epithelialization of the edges.

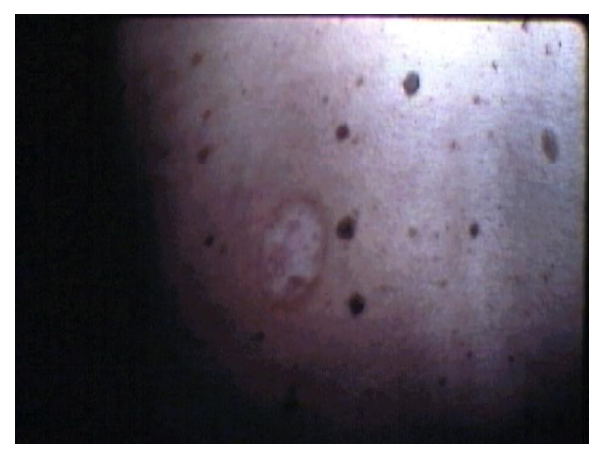

Figure 6c: The neoplastic lesion 60, 90 and 120 days after the beginning of therapy, respectively. The basal cell carcinoma regressed with dry scarring and re-epithelialization of the edges. 


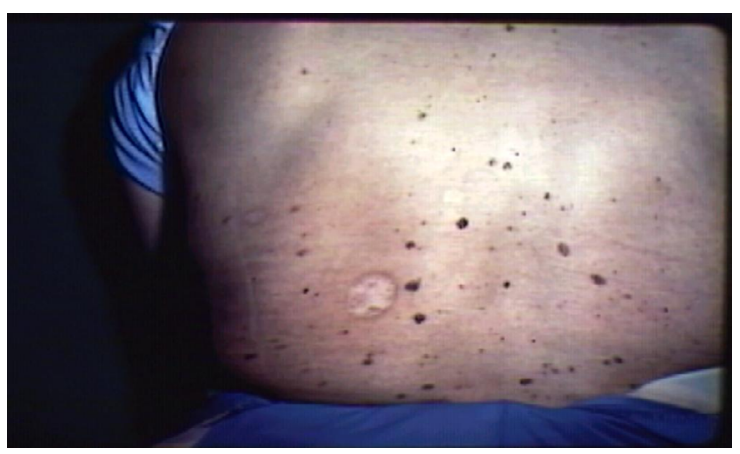

Figure 6d: The neoplastic lesion 60, 90 and 120 days after the beginning of therapy, respectively. The basal cell carcinoma regressed with dry scarring and re-epithelialization of the edges.

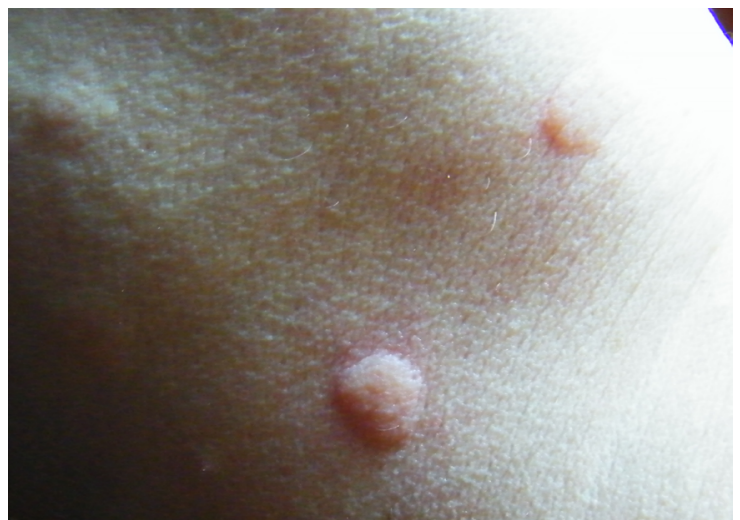

Figure 7: Example of blisters in sites of past immunogen injections in the left arm

of blood serum. This opening was repeatedly sutured, but the loss and the smell continued. On October 26, the CT scan of chest, abdomen and legs showed a large volume of liquid in the place where the tumor mass had been removed. After clinical examination, Tiklid, Persantin and Trental were prescribed. Overall, the patient was getting clinically worse. According to his family, the patient decided to discontinue any cancer treatment.

Beginning of immunological therapy: As the patient was discharged from the hospital, at the suggestion of Dr. Ferretti, the cancer treatments previously prescribed were gradually removed. Only Multicentrum (1 tablet per day), Contramal (10 drops if necessary) and Cibalgina (if necessary) were maintained. A series of wet poultices (saline solution, 1 tablespoon of salt in $500 \mathrm{ml}$ of water) were applied on the opening of the wound, to hold it open. On October 27, the first injection of Dr. Ferretti's immunogen was made and injections of immunogen were repeated at intervals ranging from a week to a month, depending on patient's reactivity. Following removal of chemotherapy and the beginning of Dr. Ferretti's therapy, the patient started feeling better and both serum leakage and the size of the opening in the thigh started reducing. After the second and third injection, made on November 11 and December 12, respectively, the size of opening, serum leakage and smell declined progressively. The thigh circumference also reduced, but in spite of these slight improvements the patient felt worse, with general fatigue, dissatisfaction with food, weight loss and psychological discomfort. The patient refused to take any kind of painkiller and occasionally felt pain in the site of surgical wound, as well as in two left thorax regions and in the left pelvic region, roughly corresponding to the sites were slight alterations were found in previous CT. On palpation, a massive enlargement could be felt in the left pelvic region, with thickening of the vas deferens, where the patient felt sharp stitches alternating with tingling.

About two weeks after the onset of these painful sensations, in urine, faeces and sweat a smell of dead rat could be perceived and Dr. Ferretti informed the patient that his therapeutic strategy contemplated this apparent worsening before the beneficial effects would appear. The patient did not believe this explanation; he became very depressed and refused to meet Dr. Ferretti again. However, on January 29 and February 13 the patient voluntarily received the fourth and fifth injections of immunogen. The following period was characterized by increased painful sensations in the locations above reported. Brief episodes of dead rat smell in urine, faeces and sweat also occurred. The emotional discomfort improved and periods of relief ensued. The thigh circumference also decreased and the functional capacity of the leg slowly recovered. On February 29, the patient received the sixth application and the painful sensations became rarer, with no bad smell. The patient began to drive a modified car and received further immunogenic injections on March 25 and 31, April 7 and 21 and May 2 , respectively. Similar episodes of pain and mood swings between depression and well-being continued, but with a definitely lower intensity and the patient were able to sleep without any drug. On June 5 , the patient received the twelfth application and a clear improvement was evident. On June 22 the thirteenth application was made and the patient for the first time reported feeling healed. He could walk without a cane. Electromyography was performed, which showed a neurological impairment due to surgery. In August 1999, the patient began physical therapy. The injections of immunogen continued until April 2000. From 2000 until 2006, the patient received an injection of immunogen every 4 months for preventive purposes. During this period further analysis were performed and no clinical signs of relapse were apparent. GG died on 2011 by other pathology.

\section{Case BS}

BS was born in 1984. On November 16, 2005, BS underwent thyroidectomy. The diagnosis was papillary carcinoma $3.7 \times 7 \mathrm{~cm}$ wide, also involving perithyroid tissues, with surgical margins infiltrated by neoplastic cells and multiple lymph node metastases. In December 2005, she received ablative metabolic radiotherapy (5550 MBq of 131 iodine), after which areas of radioalogen uptake were still present in the anterior region of the neck and in both lung fields. On January 2006, a CT-scan without contrast medium did not show densitometric changes in the thorax. In April 2006, chest and bone scan, as well as abdominal ultrasounds, were negative, however under Levothyroxine therapy, detectable values of thyroglobulin (TG, $20 \mathrm{ng} / \mathrm{ml}$ ) were suggestive of biochemical relapse. In June 2006 the patient underwent the second metabolic treatment (same parameters as the first one). After the metabolic therapy, total body scan displayed "two areas of moderate uptake in the anterior region of the neck and a widespread activity in both lung fields, significantly reduced with respect to the previous control". Due to detectable values of TG $(12 \mathrm{ng} / \mathrm{ml})$ during a TSH suppressing therapy, on July 2007 another treatment of metabolic radiotherapy was applied $(3700 \mathrm{MBq}$ of 131 Iodine, after Thyrogen administration). TSH and TG values were $145 \mathrm{and} 27 \mathrm{ng} / \mathrm{ml}$, respectively. The PET scan (370 MBq, 18F-FDG) did not display areas of radioisotope pathological accumulation suggesting lesions with high metabolic activity.

Beginning of immunological therapy: The immunological therapy 
started on March 2008 paralleling the standard follow-up therapy and is still continuing. On February 2008, just a month before the start of therapy, plasma TG concentration was $11 \mathrm{ng} / \mathrm{ml}$. On March 2008, TG concentration by needle aspiration cytology from right lymph node III-IV level was $2.0 \mathrm{ng} / \mathrm{ml}$. The cytologic diagnosis was consistent with reactive lymph node. Plasma TG concentration in successive measurements from 2008 to 2009 ranged between 7.10 and $10.9 \mathrm{ng} / \mathrm{ml}$.

On February 2009 a PET scan with 370 MBq of 18 F-FDG did not show areas of increased metabolism related with certainty to neoplastic type lesions. A hypermetabolic lymph node was however observed in the right armpit. On April 2009 a total body bone scan with 99 TcMDP $740 \mathrm{MBq}$ did not show areas of pathological accumulation of the tracer related to bone lesions. The full abdomen echography as well as the high-resolution CT (HRCT) showed no alterations worth noting. However, according to laboratory tests performed on June 2009, reactive lymph nodes were still present in the right supraclavicular region. Plasma TG concentration in successive measurements from 2009 to 2010 ranged between 2.20 and $3.40 \mathrm{ng} / \mathrm{ml}$.

The full abdomen echography as well as the chest high-resolution CT, performed on March 2010 showed no pathological changes worth noting. On June 2010, a biopsy was performed at the mediastinal VII level. The diagnosis was "reactive lymph nodes. No evidence of neoplasia “.

On December 2010, on the specific question of metastases of papillary thyroid cancer, a lymph node biopsy was performed. The report was A) reactive lymph nodes, no evidence of neoplasia, B) thymic tissue unaffected.

After the beginning of the immunological therapy, the patient experienced an increase in appetite, joy of life and energy. This allowed her to resume the work of nursery school teacher, work she still retains.

Overall treatment outcome: In some cases, such as $\mathrm{AB}$ and $\mathrm{PB}$, healing took place as a result of immunological therapy alone. In other cases, such as GG, healing occurred as a result of immunological treatment applied following conventional anti-cancer therapies, such as radiotherapy, surgery and chemotherapy. In the case BS and in the cases MV, KV and DC reported in supplementary information, healing took place as a result of the immunological therapy applied in parallel with conventional anti-cancer therapies. In the case SG, reported in the supplementary information, the immunological therapy was applied after all conventional therapies had been abandoned. Life duration increased beyond medical expectancy, associated with an acceptable life quality. Basing on the many cases treated over the years, the overall outcome of Dr. Ferretti's therapy may be depicted. In general, a substantial improvement in quality of life was observed. Starting from the $3^{\text {rd }}-5^{\text {th }}$ day after the immunogen injection, the patients felt a kind of pain awakening in the regions of neoplastic lesions. The pain lasted a few days, rarely requiring the administration of mild analgesics. Then it disappeared and the patients felt better than before the injection. Sometimes sparse itching blisters appeared in sites of past immunogen injections and in no other body sites. The blisters remained visible for 2-4 hours, then disappeared without leaving any visible sign (Figure 7). For what concerns the general effects of therapy, the marked pain decrease until total disappearance was accompanied by an increased desire to live. In some cases, the patient resumed the work activities previously interrupted because of the disease. Apparently, the therapy eliminated the systemic effects of cancer. Even in the presence of large and even increasing tumor masses, the patient maintained a state of well-being and absence of pain. An increased survival beyond the medical prognosis was also observed. Although theoretically possible, in thousands of injections, adverse reactions never occurred.

\section{Discussion}

\section{CVF, serum and therapeutic mix}

The band profile of native CVF appearing in Figure 1A showed a greater complexity than published [11]. The CVF analyzed was from the same stock as that utilized in the more recent cases. The low weight bands appearing in SDS-PAGE CVF (Figure 1C) may result from denaturation and reduction of the 70 and $75 \mathrm{kDa}$ native bands.

In both Native-PAGE S10 and S50, a $70 \mathrm{kDa}$ band is present (Figure $2 A)$. According to the filter nominal cut-off values, the band weights in the filtrate should be lower than 10 or $50 \mathrm{kDa}$, respectively. However, manufacturer's specifications indicate that a minor percentage of higher weight proteins may pass through the filter $[15,16]$. More restrictive conditions could have been realized, but this protocol was maintained since it was the one used to prepare the therapeutic mix. Seemingly, only the most abundant proteins $(70 \mathrm{kDa})$ showed up in the gel, but the presence of other less represented hight weight proteins cannot be excluded. Indeed, cut-off filter excludes high molecular weight serum proteins. However this was done on purpose by Dr. Ferretti to cut-off albumin and other high concentration proteins that could overstimulate the immune system with no relation to anti-cancer mechanisms. Moreover, as CVF inhibitors also include proteolytic enzymes, CVF fragments possibly complexed with serum low molecular weight proteins may appear in the mix. Thus the CVFserum interaction is demonstrated by both low and high molecular weight adducts.

For what concerns high molecular weight bands $(>150 \mathrm{Kda})$ in native $\mathrm{S} 10 \mathrm{~V}$ and $\mathrm{S} 50 \mathrm{~V}$, they possibly represent the products of protein interaction (Figure 3C). Bands higher than $250 \mathrm{kDa}$ (the upper weight limit of the molecular marker used) cannot be excluded (Figure 3A).

On the basis of the overall data above reported, it appears that a complex interaction occurred between CVF and filtered S10 and S50 serum. For what concerns S10V, the three bands detectable in native $\mathrm{S} 10 \mathrm{~V}(150,75$ and $70 \mathrm{kDa}$ approximately) likely arose from the products assigned to CVF or S10 in SDS-PAGE of S10V. Native S10 and CVF could interact through both proteolysis and aggregation processes and products with molecular weight higher than the gel resolution could arise. These products could result in the bands that in SDS-PAGE conditions cannot be assigned to CVF or S10. Furthermore, the native products of S10V not easily assigned to native CVF or S10 likely arose from the interaction of CVF and S10 by S-S bonds.

Interestingly, in the SDS-PAGE condition, the products assignable to CVF were fewer and less abundant in S50V than in S10V. This different molecular rearrangement can be explained by the hypothesis that serum contained proteases with molecular weight higher than 10 $\mathrm{kDa}$, together with protease inhibitors with molecular weight higher than $50 \mathrm{kDa}$. Therefore, while $\mathrm{S} 10$ contained few proteases and almost no inhibitors, S50 contained many proteases and few inhibitors. As a consequence, larger protein degradation occurred in S50V than in S10V.

The results concerning freezing (see Figures $4 \mathrm{~A}$ and $4 \mathrm{~B}$ ) indicate that freezing may be a good preservation method for the therapeutic mix, allowing not adding Thimerosal, a germicide previously utilized, but no more allowed by the Italian health authorities.

\section{Immunological therapy}


Dr. Ferretti's therapy is aimed at balancing the various molecular components of the immune system, so as to restore its natural antitumor activity. According to his hypothesis, this is obtained by stimulating the production of antibodies that neutralize the excess inhibitors, thus reactivating the lytic cascade and the cell-mediated toxicity. If the immune response elicited is not adequate to eliminate the transformed cells, a tumor develops. Even in this case the improvement of the immune function may be beneficial in slowing down tumor development and reducing its systemic effects. The beneficial effects of Dr. Ferretti's therapy might be explained by alternative hypotheses, such as unspecific effects of the immune reaction. For instance, diphtheria toxin (DT) showed anti-tumor activity in mice [17] and in humans [18]. Even a nontoxic mutant of DT exerted some degree of biological anti-tumor activity [19]. Intravesical induction and maintenance of Bacillus Calmette-Guerin has proven to reduce tumor recurrence and progression [20]. Concomitant active tuberculosis prolongs the patient survival in non-small cell lung cancer [21]. In mice, the anticancer effects of cyclophosphamide are in part immune mediated, as cyclophosphamide alters the composition of microbiota in the small intestine and induces the translocation of selected species of Gram-positive bacteria into secondary lymphoid organs, thus stimulating immune responses [22]. However, some data point to a specific immune mediated link between Dr. Ferretti's immunogen and malignancy processes. First, the injected immunogen initially increases pain in the neoplastic lesions and no elsewhere. Seemingly, the immunogen-induced antibodies cross-react with malignancy processes. Second, blisters form in sites of past immunogen injections. Likely, immunogen and/or cancer induced antibodies cross-react with the injected immunogen. Both events are compatible with a specific link between Dr. Ferretti's immunogen and malignancy processes. This link deserves further studies, as it could provide the basis of new therapeutic strategies. Most cancer vaccines contain antigens normally expressed by the host. This may lead the host to develop immunological tolerance [23]. In the present therapeutic mix the epitopes eliciting antibodies are definitely non-self and unlikely to induce immunological tolerance. Moreover, neither toxicity nor adverse effects were ever found in the many patients treated up to now. In addition, the hypothesized link between immunogen and malignancy may also provide a diagnostic tool, as the sites of unknown secondary lesions become apparent through the increased pain elicited by immunogen injections. Possibly, the therapy mainly affects the transformed cells peripheral to the tumor mass, preventing their aggression against normal cells. Even if tumor mass increases, the increase possibly occurs through the sole circulating nutrients, without affecting the normal peri-tumoral tissue. In general, besides a state of general well-being, decrease or disappearance of pain, new energy and a new positive sense of life, the patients also reported a better resistance to infectious diseases, which is consistent with the improvement of the immune function.

\section{Conclusion}

Dr. Ferretti's therapy is aimed at balancing the various molecular components of the immune system, so as to restore its natural antitumor activity. This therapy likely acts on tumors through improving the immune function and therefore the general state of the patient and his quality of life, as consistently observed. A specific immune mediated link between Dr. Ferretti's immunogen and malignancy processes is suggested. This link could provide the basis of new therapeutic and diagnostic strategies.

\section{Future perspectives of Dr. Ferretti's immunotherapy}

The important results obtained by Dr. Ferretti deserve further studies and researches. Dr. Ferretti's therapy and mix are protected by US patent [6], previously assigned to the Fernando and Anna Foundation, Chicago IL (US). The present assignee is the Fondazione Fernando e Anna Ferretti, a nonprofit institution according to the Italian law. This institution is willing to grant the use of the patent for scientific and commercial purposes.

\section{References}

1. Vergati M, Intrivici C, Huen NY, Schlom J, Tsang KY (2010) Strategies for cancer vaccine development. J Biomed Biotechnol 596432.

2. Perez SA, von Hofe E, Kallinteris NL, Gritzapis AD, Peoples GE et al. (2010) A new era in anticancer peptide vaccines. Cancer 116: 2071-2080.

3. Finn OJ (2012) Immuno-oncology: understanding the function and dysfunction of the immune system in cancer. Ann Oncol 23: 6-9.

4. Quezada SA, Peggs KS (2013) Exploiting CTLA-4, PD-1 and PD-L1 to reactivate the host immune response against cancer. Br J Cancer 108: 15601565.

5. Topalian SL, Weiner GJ, Pardoll DM (2011) Cancer Immunotherapy Comes of Age. J Clin Oncol 29: 4828-4836.

6. Ferretti F, Ferretti A (2010) Compositions and methods for treating cancer. Patent No. US7,723,292 B2

7. Shishido SN, Varahan S, Yuan K, Li X, Fleming SD (2012) Humoral innate immune response and disease. Clin Immunol 144: 142-158.

8. Qu H, Ricklin D, Lambris JD (2009) Recent developments in low molecular weight complement inhibitors. Mol Immunol 47: 185-195.

9. Chen S, Caragine T, Cheung NK, Tomlinson S (2000) CD59 expressed on a tumor cell surface modulates decay-accelerating factor expression and enhances tumor growth in a rat model of human neuroblastoma. Cancer Res 60: 3013-3018.

10. Liu Y, Zeng G (2012) Cancer and Innate Immune System Interactions: Translational Potentials for Cancer Immunotherapy. J Immunother 35: 299308.

11. Kock MA, Hew BE, Bammert H, Fritzinger DC, Vogel CW (2004) Structure and function of recombinant cobra venom factor. J Biol Chem 279: 30836-30843.

12. Hains PG, Broady KW (2000) Purification and inhibitory profile of phospholipase A2 inhibitors from Australian elapid sera. Biochem J 346: 139-146.

13. Baldrick P, Richardson D, Wheeler AW (2002) Review of L-tyrosine confirming its safe human use as an adjuvant. J Appl Toxicol 22: 333-344.

14. Rais I, Karas M, Schägger H (2004) Two-dimensional electrophoresis for the isolation of integral membrane proteins and mass spectrometric identification. Proteomics 4: 2567-2571.

15. http://www.millipore.com/userguides/tech1/centrifugal_ivd_userguide

16. ht t p:// w w w. millipore.com/publications.nsf / a73664f9f981af8c852569b9005b4eee/f01ae45d5551b0588525792200680bb b/\$FILE/PB2778ENEU\%20MM.pdf

17. Buzzi S, Maistrello I (1973) Inhibition of growth of Erlich tumors in Swiss mice by diphtheria toxin. Cancer Res 33: 2349-2353.

18. Buzzi S (1982) Diphtheria toxin treatment of human advanced cancer. Cancer Res 42: 2054-2058.

19. Buzzi S, Rubboli D, Buzzi G, Buzzi AM, Morisi C et al. (2004) CRM197 (nontoxic diphtheria toxin): effects on advanced cancer patients. Cancer Immunol Immunother 53: 1041-1048.

20. Ajili F, Darouiche A, Chebil M, Boubaker S (2013) The efficacy of intravesica bacillus Calmette-Guerin in the treatment of patients with pT1 stage nonmuscle-invasive bladder cancer. Ultrastruct Pathol 37: 278-283.

21. Kuo $\mathrm{CH}$, Lo CY, Chung FT, Lee KY, Lin SM et al. (2012) Concomitant active tuberculosis prolongs survival in non-small cell lung cancer: a study in a tuberculosis-endemic country. PLoS One 7: e33226

22. Viaud S, Saccheri F, Mignot G, Yamazaki T, Daillère R, et al. (2013) The intestinal microbiota modulates the anticancer immune effects of cyclophosphamide. Science 342: 971-976. 
Citation: Facchin F, Ciano M, Canaider S, Ferretti F, Ferretti A (2014) Treating Cancer with Snake Venom and Serum: Case Series. Altern Integ Med 3: 167. doi:10.4172/2327-5162.1000167

23. Church SE, Jensen SM, Twitty CG, Bahjat K, Hu HM et al. (2011) Multiple Vaccinations: Friend or Foe. Cancer J 17: 379-396.
Citation: Facchin F, Ciano M, Canaider S, Ferretti F, Ferretti A (2014) Treating Cancer with Snake Venom and Serum: Case Series. Altern Integ Med 3: 167. doi:10.4172/2327-5162.1000167
Submit your next manuscript and get advantages of OMICS Group submissions

\section{Unique features:}

- User friendly/feasible website-translation of your paper to 50 world's leading languages

Audio Version of published paper

Digital articles to share and explore

Special features:

- 350 Open Access Journals

30,000 editorial team

21 days rapid review process

Quality and quick editorial, review and publication processing

Indexing at PubMed (partial), Scopus, EBSCO, Index Copernicus and Google Scholar etc

- Sharing Option: Social Networking Enabled

- Authors, Reviewers and Editors rewarded with online Scientific Credits

- Better discount for your subsequent articles

Submit your manuscript at: http://www.omicsonline.org/submission 